Жалсанова Валентина Гурожаповна

кандидат социологических наук, доцент, старший научный сотрудник Федерального государственного бюджетного учреждения науки Институт монголоведения, буддологии и тибетологии Сибирского отделения Российской академии наук (ИМБТ СО РАН)

\section{МЕЖНАЦИОНАЛЬНЫЕ ОТНОШЕНИЯ В РЕСПУБЛИКЕ БУРЯТИЯ В СОВРЕМЕННЫЙ ПЕРИОД (ПО МАТЕРИАЛАМ СОЦИОЛОГИЧЕСКОГО ИССЛЕДОВАНИЯ) [1]}

\section{Аннотация}

В статье приведены данные массового опроса населения, проведенного в Республике Бурятия в 2018-2019 ге. Исследование показало, что в регионе сохраняются позитивные межнациональные отношения, которые оцениваются населением как более благоприятные по сравнению с Российской Федерацией в целом. Наличие критических оценок обусловлено не столько напряженностью в отношениях между народами, проживающими на территории Бурятии, сколько социально-экономическим кризисом, вызывающим ухудшение социального самочувствия населения. Республика Бурятия как часть российского государства в целом обеспечивает реализацию задач национальной политики по консолидации общества. Этносоциальные и этнополитические процессы не несут в себе отрицательный заряд, который мог бы вызвать дестабилизацию в сфере межнациональных отношений. Исторически в Бурятии сложился благоприятный фон для этнических контактов, что способствует обеспечению межнационального согласия в современный период.

Ключевые слова:

Бурятия, городское население, сельское население, межнациональные отношения, межнациональное согласие, этносоциальные и этнополитические процессы, русские, буряты.

\section{Zhalsanova Valentina Gurozhapovna}

PhD in Social sciences, Associate Professor, Senior Research Fellow Institute for Mongolian, Buddhist and Tibetan Studies of the Siberian Branch of the Russian Academy of Sciences (IMBTS SB RAS)

INTER-ETHNIC RELATIONS IN THE REPUBLIC OF BURYATIA IN THE MODERN PERIOD (THE RESULTS OF A SOCIOLOGICAL STUDY) [1]

Summary:

The study presents data from a mass survey of the population conducted in the Republic of Buryatia in 20182019. The study showed that positive inter-ethnic relations persist in the region, which are estimated by the population as more favorable in comparison with the Russian Federation as a whole. The presence of critical assessments is caused not so much by tensions between the peoples living in the territory of Buryatia as by the socio-economic crisis that causes a deterioration in the social well-being of the population. The $R e$ public of Buryatia as part of the Russian state ensures the implementation of the national policy tasks of consolidating society. Ethnosocial and ethnopolitical processes do not carry a negative charge, which could cause destabilization in the field of inter-ethnic relations. Historically, Buryatia formed a favorable back ground for inter-ethnic relationships and nowadays it results in inter-ethnic harmony.

Keywords:

Republic of Buryatia, urban population, rural population, inter-ethnic relations, inter-ethnic harmony, ethnosocial and ethnopolitical processes, Russians, Buryats.

Введение. Национальные республики в современной России представляют собой особые субъекты Федерации, где состояние сферы межнациональных отношений оказывает влияние на все области социальных взаимодействий. Республика Бурятия, традиционно относящаяся к регионам со спокойными и благоприятными отношениями между народами, проживающими на ее территории, продолжает демонстрировать сохранение позитивного фона в данной сфере. Тем не менее, «проблемы, связанные с сохранением межнационального согласия, требуют к себе внимания со стороны исследователей и органов государственной власти всех уровней с целью решения, а также прогнозирования основных тенденций развития, стабилизации этнополитического и этнокультурного пространства» [2, с. 128]. Мониторинговые исследования в формате как экспертной панели, так и массового опроса способствуют решению задачи обеспечения межнационального согласия, декларируемой Стратегией государственной национальной политики РФ на период до 2025 года, утвержденной указом Президента РФ №1666 от 19.12.2012г. [3].

Представленная статья основана на данных социологического исследования, проведенного в 2018-2019 гг. в рамках проекта «Межнациональное согласие в Республике Бурятия в изменяющихся социально-политических условиях». Исследование было реализовано социологической группой Института монголоведения, буддологии и тибетологии Сибирского отделения Российской академии наук при поддержке Российского фонда фундаментальных исследований 
[4]. Первая часть исследования была проведена в 2018 г., когда было опрошено городское население (500 чел.), его результаты опубликованы в виде отдельных статей [5; 6]. В 2019 г. были опрошены сельские жители в количестве 400 человек. В итоге общая выборка (все население Республики Бурятия) составила 900 респондентов. Была использована стратифицированная многоступенчатая выборка с применением квотных значений по взаимосвязанным параметрам на последней ступени отбора респондентов - пол, возраст, национальность. На первой ступени были отобраны города и сельские муниципальные районы по следующим критериям: удаленность от столицы региона, национальный состав, социально-экономические характеристики. В итоге в выборку попали столица г. Улан-Удэ, г. Кяхта, г. Северобайкальск, Баргузинский, Еравнинский, Заиграевский, Кабанский, Тарбагатайский и Хоринский районы. На второй ступени были отобраны населенные пункты внутри районов. На третьей ступени отбор осуществлялся согласно квотным значениям. Всего было опрошено 25,1 \% бурят, 70,0 \% русских и 4,8 \% представителей других национальностей; 46,6 \% мужчин, 53,4 \% женщин. Квоты по возрастам были распределены по пяти группам: 18-29 лет 28,8 \%, 30-39 лет - 18,6 \%, 40-49 лет - 16,9 \%, 50-59 лет$18,4 \%, 60$ лет и старше - 17,3 \%. Необходимое число опрашиваемых и параметры отбора определялись на основе Итогов Всероссийской переписи населения 2010 г.

Особенности этносоциального и этнополитического развития Бурятии. Республика Бурятия является субъектом Российской Федерации и с ноября 2018 г. входит в состав Дальневосточного федерального округа. Административно-хозяйственным и культурным центром республики является г. Улан-Удэ. Бурятия расположена в южной части Восточной Сибири, южнее и восточнее озера Байкал. На юге Республика Бурятия граничит с Монголией, на юго-западе - с Республикой Тыва, на северо-западе - с Иркутской областью, на востоке - с Забайкальским краем. На территории республики расположены 21 муниципальный район, 2 городских округа, 263 городских и сельских поселений. Численность постоянного населения на 1 января 2013 г. составила 971,8 тыс. чел., средняя плотность населения - 3,0 чел. на 1 кв. км. Национальный состав республики, по данным переписи 2010 г., следующий: русские - 66,1 \%, буряты - 30 \%, украинцы - 0,6 \%, другие национальности - 3,3\%. Также проживают представители коренных малочисленных народов эвенки и сойоты, которые составляют 0,7 \% от общей численности населения [7].

Этническая конфигурация в Бурятии сложилась таким образом, что наблюдается значительное преобладание русского и бурятского населения. Это привело к тому, что основной фон этносоциальных процессов и межэтнических отношений в регионе обусловлен особенностями взаимодействия данных народов. Дополнительным фоном является социальное положение народов, отнесенных к коренным и малочисленным, а именно эвенков и сойотов. Современность добавила еще один фрактор, оказывающий влияние на состояние межнациональных отношений, - интенсифицирующиеся миграционные процессы. Несмотря на то, что Бурятия не является зоной массового притока мигрантов из других стран, данный фактор обладает некоторым дестабилизирующим потенциалом [8].

Республика Бурятия никогда не относилась к регионам с напряженными и конфрликтными межнациональными отношениями. Даже в условиях 90-х гг. прошлого столетия, когда на фоне распада Советского Союза в разных регионах страны наблюдалось развитие этнического ренессанса, выражавшегося в росте национального самосознания народов и проявлении центробежных тенденций, в Бурятии удалось сохранить позитивный фон межнациональных отношений, «под которыми следует понимать весь комплекс устойчивых контактов и взаимодействий между этносами в едином социальном пространстве, в структуре экономических, социальных, политических, культурно-духовных процессов, конституирующих социальную организацию общества» [9, с. 83]. Возможно, такое развитие было обусловлено тем, что, если в некоторых национальных регионах страны рост национального самосознания чаще был характерен для титульного этноса, и закладывались основы для конфронтации с другими народами, в первую очередь с русским, то в Бурятии создавались условия по возрождению всех этносов, проживающих на ее территории [10]. По мнению М.Н. Балдано, процессы национально-культурного возрождения бурятского народа шли, опираясь на интеллектуальные традиции конца XIX - начала XX в., в первую очередь идеи панмонголизма [11]. В целом подчеркивая синусоидный характер данных процессов, она отмечает, что «в настоящее время наблюдается спад, но это вовсе не значит, что оно исчезло совсем. При новых обстоятельствах оно может актуализироваться» [12, с. 56]. Тем не менее, объединительный проект конструирования общемонгольской этнополитической системы на сегодняшний день иллюзорен, так как не имеет массовой поддержки [13].

Борьба за доминирование, поиск приоритетов для этнических групп часто становятся распространенной практикой в межнациональных отношениях [14]. В Бурятии они не получили развития. Нежизнеспособность подобных этнополитических практик в республике является след- 
ствием разных фракторов, в первую очередь особенности исторического и культурного взаимодействия между русским и бурятским народами, которое характеризуется преобладанием положительного опыта.

Таким образом, этносоциальные и этнополитические процессы в Республике Бурятия, несмотря на актуализацию этничности в первые годы постсоветского развития, протекали в русле преобладания позитивных межнациональных отношений.

Межнациональные отношения в оценках населения. Результаты массового опроса демонстрируют сохранение позитивных тенденций во взаимодействиях между народами. Респондентам было предложено дать оценку межнациональных отношений в России и Бурятии исходя из выбора между пятью значениями: «доброжелательные», «спокойные», «внешне спокойные, но внутренне напряженные», «напряженные» и «на грани открытых столкновений» (таблица 1).

Таблица 1 - Оценка состояния межнациональных отношений в России и Бурятии, \%

\begin{tabular}{|l|c|c|c|c|c|c|}
\hline & \multicolumn{3}{|c|}{ Российкая Федерация } & \multicolumn{3}{c|}{ Республика Бурятия } \\
\cline { 2 - 7 } & $\begin{array}{c}\text { городское } \\
\text { население }\end{array}$ & $\begin{array}{c}\text { сельское } \\
\text { население }\end{array}$ & $\begin{array}{c}\text { все } \\
\text { население }\end{array}$ & $\begin{array}{c}\text { городское } \\
\text { население }\end{array}$ & $\begin{array}{c}\text { сельское } \\
\text { население }\end{array}$ & $\begin{array}{c}\text { все } \\
\text { население }\end{array}$ \\
\hline доброжелательные & 5,4 & 9,5 & $\mathbf{7 , 2}$ & 11,8 & 15,5 & $\mathbf{1 3 , 4}$ \\
\hline спокойные & 35,0 & 36,3 & $\mathbf{3 5 , 6}$ & 49,0 & 53,8 & $\mathbf{5 1 , 1}$ \\
\hline $\begin{array}{l}\text { внешне спокойные } \\
\text { но внутренне } \\
\text { напряженные }\end{array}$ & 42,0 & 35,0 & $\mathbf{3 8 , 9}$ & 30,2 & 19,5 & $\mathbf{2 5 , 4}$ \\
\hline напряженные & 9,0 & 10,5 & $\mathbf{9 , 7}$ & 3,2 & 3,0 & $\mathbf{3 , 1}$ \\
\hline $\begin{array}{l}\text { на грани открытых } \\
\text { столкновений }\end{array}$ & 1,0 & 1,5 & $\mathbf{1 , 2}$ & 0,8 & 0,5 & $\mathbf{0 , 7}$ \\
\hline $\begin{array}{l}\text { Затрудняюсь } \\
\text { ответить }\end{array}$ & 7,6 & 7,2 & $\mathbf{7 , 4}$ & 5,0 & 7,7 & $\mathbf{6 , 2}$ \\
\hline
\end{tabular}

Как видно из таблицы, по мнению респондентов, и в России, и в Бурятии практически нет угроз для возникновения напряженности и конфликтов в сфере межнациональных отношений, так как варианты ответов с отрицательными значениями - «напряженные» и «на грани открытых столкновений» - были выбраны минимальным количеством опрошенных. Также межэтническая ситуация в Бурятии оценивается более положительно, нежели в России, доля выбравших положительные значения - «доброжелательные» и «спокойные» - в сумме составила 64,5 \% и 42,8 \% соответственно. Полученные данные демонстрируют, тем не менее, отсутствие единства в оценках, так как достаточно высока доля выбравших серединное значение «внешне спокойные, но внутренне напряженные», которое несет в себе некоторый отрицательный заряд, потенцию к вероятному ухудшению состояния межнациональных отношений.

В целом полученные данные подтверждают общероссийскую тенденцию снижения актуальности межнациональных отношений в восприятии населением окружающей социальной действительности [15, с. 23-24]. По мнению авторов монографии «Межнациональное согласие в общероссийском и региональном измерении. Социокультурный и религиозный контексты», это может быть связано с переключением внимания СМИ на внешнего врага, накоплением опыта общения с инокультурными мигрантами [15, с. 25].

Исследование показало, что различия в территориальной принадлежности респондентов (городские / сельские) оказало влияние на оценки. Хотя следует сразу отметить, что при оценке состояния межнациональных отношений в России ответы и горожан, и сельчан не отличались значительно и были близки к ответам по всей выборке. Расхождения наблюдаются при оценке ситуации в Бурятии: сельские респонденты чаще выбирали положительные значения. Так, варианты «доброжелательные» и «спокойные» отметило 69,3 \% опрошенных сельчан и 60,8 \% горожан. При выборе отрицательных значений доли городских и сельских респондентов практически совпали. Наибольшей разница оказалась при выборе значения «внешне спокойные, но внутренне напряженные» - доля горожан здесь превысила долю сельчан на 10,7 \% (30,2 \% и 19,5 \% соответственно). По нашему мнению, на подобный расклад оказало влияние два фрактора. Вопервых, для городского населения в постсоветский период стало характерно увеличение численности за счет миграционного притока из сельских районов республики. Среди сельских мигрантов высокой является доля бурят, тогда как для русских характерно другое миграционное поведение - выбытие в другие регионы. Так, в период между Всероссийскими переписями населения 2002 и 2010 гг. численность бурятского населения Улан-Удэ, являющегося столицей и самым крупным по численности городом, увеличилась со 115585 до 128968 чел., и произошло снижение численности русского населения с 255549 до 251071 чел. Таким образом, внутрирегиональ- 
ная миграция наряду с миграцией бурят из Усть-Ордынского и Агинского бурятского округов изменила этнический состав населения г. Улан-Удэ. Во-вторых, мигранты, прибывающие в республику, также предпочитают оседать в городе. Причина предпочтительности города как для внутренних, так и для внешних мигрантов одна - ухудшение социально-экономического положения сельских территорий республики. В итоге эти два фрактора способствуют тому, что город становится зоной усиления межэтнических контактов, которые сопровождаются не только положительными, но и отрицательными проявлениями. Тем не менее, отметим, что, несмотря на некоторый критицизм в оценках горожан в целом для них характерно преобладание положительных оценок.

Этническая принадлежность респондентов не оказала сильного влияния на оценки межнациональных отношений в России и Бурятии. Наблюдаются незначительные расхождения, которые выражаются в более критических оценках бурятами ситуации в России и, наоборот, преобладают критические оценки русскими ситуации в Бурятии (таблица 2).

Таблица 2 - Оценка состояния межнациональных отношений в России и Бурятии в зависимости от этнической принадлежности респондентов, \%

\begin{tabular}{|l|c|c|c|c|c|c|}
\hline & \multicolumn{3}{|c|}{ В России } & \multicolumn{3}{c|}{ В Бурятии } \\
\cline { 2 - 7 } & буряты & русские & другие этносы & буряты & русские & другие этносы \\
\hline доброжелательные & 4,4 & 8,1 & 9,3 & 11,9 & 13,8 & 16,3 \\
\hline спокойные & 33,6 & 36,3 & 34,9 & 57,1 & 49,4 & 46,5 \\
\hline $\begin{array}{l}\text { внешне спокойные } \\
\text { но внутренне } \\
\text { напряженные }\end{array}$ & 43,8 & 36,8 & 41,9 & 27,0 & 24,6 & 27,9 \\
\hline напряженные & 11,1 & 9,5 & 4,6 & 0,9 & 3,9 & 2,3 \\
\hline $\begin{array}{l}\text { на грани открытых } \\
\text { столкновений }\end{array}$ & 0,9 & 1,3 & 2,3 & - & 0,8 & 2,3 \\
\hline $\begin{array}{l}\text { Затрудняюсь } \\
\text { ответить }\end{array}$ & 6,2 & 8,0 & 7,0 & 3,1 & 7,5 & 4,6 \\
\hline
\end{tabular}

Причиной отсутствия значительных расхождений в оценках бурят и русских, на наш взгляд, является то, что в республике не наблюдается чрезмерная диффреренциация в социально-экономическом положении данных народов. И, хотя имеются фракторы, оказывающие негативное воздействие на состояние межнациональных отношений [16], они оказываются не столь сильными по своему воздействию. Косвенным подтверждением отсутствия напряженности в этой сорере могут послужить ответы на вопрос «Приходилось ли Вам испытывать неприязнь из-за своей национальности?». Подавляющее большинство опрошенных $(84,0$ \%) ответило на него отрицательно. Также значительное количество респондентов дало утвердительные ответы на вопрос о том, является ли многонациональность России положительным фрактором. 65,1 \% согласились, что многонациональность нашего государства приносит пользу, из них 22,8 \% выбрали вариант «безусловно, больще пользы» и 42,3 \% - «скорее больще пользы». Еще одним консолидирующим фактором становится отсутствие религиозного антагонизма в регионе, несмотря на то, что здесь представлены разные конфессии, среди которых наиболее многочисленными являются последователи православия, древлеправославия, буддизма и бурятского шаманизма. На вопрос «Испытываете ли Вы недоверие к представителям других религий?» 71,4 \% опрошенных ответили «скорее не испытываю» $(22,2$ \%) и «не испытываю» $(49,2$ \%).

По нашему мнению, можно согласиться с выводом Л.М. Дробижевой и Т.А. Титовой, который они сделали относительно Республики Татарстан, и применить его к Бурятии. По результатам исследования межэтнических отношений они пришли к заключению о том, что «Татарстан по-прежнему является для отечественного и мирового пространства опытом, демонстрирующим значение исторически накопленного ресурса «жить вместе» и умения власти регулировать противоречия, которые неизбежно встречаются в многонациональном, полиэтническом обществе» [17, с. 10]. Действительно, и в Бурятии имеет место быть подобный опыт позитивного умения «жить вместе», который наряду с грамотной национальной политикой, проводимой органами государственного управления и различными общественными организациями, национально-культурными центрами, продуцирует отношения солидарности между всеми народами республики.

Заключение. Сохранение гармоничных межнациональных отношений в национальном регионе является важной задачей общества и государства. Исследование показало, что, несмотря на позитивные оценки, население Республики Бурятия демонстрирует наличие внутренней напряженности в сфрере взаимоотношений между народами. Трансформация картины этносоциальной стабильности может быть вызвана изменением характера межгрупповых связей, текущей экономической ситуацией, отсутствием четкой инструментальной политики в области государственной 
идеологии [18]. Наличие скрытой, неявной напряженности в межнациональных отношениях в Республике Бурятия, скорее всего, обусловлено ростом социальной напряженности в обществе вследствие социально-экономического кризиса. С одной стороны, отсутствие социальной диффреренциации между двумя наиболее крупными этническими группами русских и бурят является фактором, сдерживающим проявление конфликтности. С другой стороны, ухудшение социально-экономического положения оказывает негативное влияние на социальное самочувствие населения в целом, и на восприятие сфреры межнациональных отношений, в частности. Тем не менее, общий благоприятный характер этнических контактов в Республике Бурятия способствует минимизации негативных факторов и дальнейшему поиску путей и способов обеспечения межэтнического согласия в регионе. Этническое и этнокультурное разнообразие в современных условиях является важнейшим ресурсным потенциалом, способным обеспечить не только стабильное развитие межнациональных отношений, но и оказать позитивное влияние на социально-экономическую сфреру.

\section{Ссылки:}

1. Работа выполнена при поддержке РФФИ-р_а 18-411-030010118 «Межнациональное согласие в Республике Бурятия в изменяющихся социально-политических условиях».

2. Петрова Е.В. Мониторинг межнациональных отношений в полиэтнических регионах: организация работы экспертной панели в Республике Бурятия // Вестник Бурятского научного центра Сибирского отделения Российской академии наук. 2017. № 2(26). С. 125-129.

3. Указ Президента РФ от 19 декабря 2012 г. N 1666 "О Стратегии государственной национальной политики Российской Федерации на период до 2025 года" [Электронный ресурc]. URL: http://base.garant.ru/70284810/ (дата обращения: 14.02.2020)

4. Руководитель проекта - д. социол. н., доц. Петрова Е.В., исполнители - к. социол. н., доц. Жалсанова В.Г., к. социол. н. доц. Бадараев Д.Д., к. социол. н. Бильтрикова А.В., к. фрилос. н. Дашибалова И.Н., к. и. н. Бреславский А.С.

5. Жалсанова В.Г., Бадараев Д.Д., Бреславский А.С. Межнациональные отношения в Республике Бурятия в оценках городского населения (по материалам социологического исследования) // Теория и практика общественного развития. 2019. № 2. С. 22-28. DOI: https://doi.org/10.24158/tipor.2019.2.3.

6. Петрова Е.В., Бильтрикова А.В., Дашибалова И.Н. Доверие городского населения Республики Бурятия как индикатор межнационального согласия в регионе // Вестник развития науки и образования. 2019. № 1. С. 9-18.

7. Краткие сведения о Бурятии [Электронный ресурc]. URL: https://egov-buryatia.ru/about_republic/short-about-rb/ (дата обращения: 14.02.2020).

8. Петрова Е.В., Жалсанова В.Г., Бильтрикова А.В. Мигранты в Бурятии: оценки принимающего сообщества // Социальная компетентность. 2019. Т. 4. № 3(13). С. 292-298

9. Рандалов Ю.Б. Современные национальные отношения в Бурятии // Республике Бурятия - 80 лет. Улан-Удэ, 2003.

10. Базаров Б.В. Бурятия в XX-XXI вв.: от национальной автономии к современной республике // Республике Бурятия 95 лет: сб. науч. ст. / науч. ред. Б.В. Базаров. Улан-Удэ: Изд-во БНЦ СО РАН, 2018. С. 3-6.

11. Панмонголизм - это идеология объединения монгольских народов в рамках единого государства, атрибутированная бурятской интеллигенцией в 1920-х гг. В настоящее время чаще подразумевается сотрудничество монгольских народов в рамках культурного пространства.

12. Балдано М.Н. Этнокультурные и этнополитические процессы в Бурятии в 1990-х гг. // Республике Бурятия - 95 лет: сб. науч. ст. / науч. ред. Б.В. Базаров. Улан-Удэ: Изд-во БНЦ СО РАН, 2018. С. 56-58.

13. Балдано М.Н. Идея создания единого монгольского государства как проект нациестроительства // Монгольская империя и кочевой мир. Кн. 2: сб. ст. Улан-Удэ: Изд-во БНЦ СО РАН, 2005. С. 276-286.

14. Pettigrew T.F., Tropp L.R. When groups meet: The dynamics of intergroup contact. New York: Psychology Press, 2011.

15. Межнациональное согласие в общероссийском и региональном измерении. Социокультурный и религиозный контексты: [монография] / Отв. ред. Л.М. Дробижева. М.: ФНИСЦ РАН, 2018.

16. Петрова Е.В. Межнациональное согласие в Республике Бурятия: оценки и мнения участников экспертной панели // Известия Иркутского государственного университета. Серия: Политология. Религиоведение. 2017. Т. 21. С. 118-125.

17. Дробижева Л.М., Титова Т.А. Социально-культурный контекст межнациональных (межэтнических) отношений в Республике Татарстан // ИНАБ. 2019. № 1. Межнациональные отношения в республиках Российской Федерации: пример Татарстана и Саха (Якутии). С. 7-23. DOI: https://doi.org/10.19181/inab.2019.1.1

18. Дашибалова И.Н. Тренды этносоциальной стабильности в Республике Бурятия (по данным социологического исследования) [Электронный ресурс] // Тренды и управление. 2018. № 4. С. 25-32. URL: http://e-notabene.ru/ptu/article_28497.html (дата обращения: 17.01.2018).

Редактор, переводчик: Невзорова Наталья Викторовна 